\section{REFERENCES}

1. Australian Bureau of Statistics. Labour Force Statistics. Canberra: AGPS, 2001. Catalogue no. 6204.0.

2. Maslow A. Toward a Psychology of Being. Princeton, NJ: Van Nostrand, 1968.

3. Kenkel DS. Health behavior, health knowledge, and schooling. Journal of Political Economy 1991; 99(2): 287-305.

4. Schultz T Paul. Benefits of Educating Women. World Bank, Background Papers Series. Washington, DC: Education and Employment Division, Population and Human Resources Department, 1989.

5. Quiggin J. (1996), Great Expectations: Microeconomic Reform and Australia. St Leonards, NSW: Allen and Unwin, 1996.

6. Rees S and Rodley G (editors). The Human Costs of Managerialism. Sydney: Pluto Press, 1995.

7. Quiggin J. Resolving the University Crisis-Submission to the Inquiry of the Senate Employment, Workplace Relations,
Small Business and Education Committee into the capacity of public universities to meet Australia's higher education needs. Canberra: Commonwealth of Australia, 2001.

8. Australian Council of Social Service. Generating Jobs: Fifteen Strategies for Reducing Unemployment in Australia, Information Paper. Sydney: ACOSS, 2001.

9. Kendall $\mathrm{L}$. The final report of the policy forum on the future of health and healthcare in the UK. London: Institute for Public Policy Research, 2000.

10. Spoehr J and Quiggin J. 'The Promise of a Social Dividend: Quality Jobs and Services for the 21st Century. Adelaide: Public Service Association of South Australia State Budget Submission, 2001.

11. Australian Bureau of Statistics. Schools Australia 1999. Canberra: AGPS, 2000. Catalogue no. 4221.0.

12. Chifley Research Centre. An Agenda for the Knowledge Nation: Report of the Knowledge Nation Taskforce, Canberra: Chifley Research Centre, 2001.

\title{
SOCIAL INCLUSION AND THE PUBLIC HEALTH:THE CASE FOR PARTNERSHIPS
}

\author{
Ian Webster, $A O$ \\ Emeritus Professor \\ University of New South Wales
}

Governments of both the right and left espouse community participation as a means of engaging with their constituencies. Concepts such as social capital, social justice, social participation, social coalition, ${ }^{1}$ equity, and communitarianism, are frames through which social policies are viewed. These directions in social policy ('whole of government') approaches in Australia; the 'third way' and 'joined-up communities' in the United Kingdom; and related concepts of $360^{\circ}$ accountability, ${ }^{2}$ are relevant to the way the health system will be organised in the future.

In the early 1980s, the commonwealth government established national health goals and targets. ${ }^{3}$ States too, defined targets, goals, and outcomes for heath programs. These were managed approaches, suggesting that health improvement could be engineered. Tweak the knobs on the grand dial and health would then be distributed. Implicit in this thinking is the belief that the whole population is homogenous and that its health can be managed from the top down.

The community, however, is not so constructed. Rather, it is many communities-communities interacting with each other and within themselves-each with their own patterns of health. Inner-city communities are different from outer urban communities, and both of these are different from rural communities. There are the marked differences between Aboriginal and non-Aboriginal communities, and between migrant groups. There are also masked differences. For example, in the South West of Sydney the health of the population is about the same as the average for New South Wales, but the massed data belie the poor health of the Australian-born residents locked into poverty. Their predicament is diluted by the better health of migrant populations. ${ }^{4}$

By attending to the health needs of particular communities, overall population health can be improved. This is not to deny the importance of mass campaigns such as immunisation, which depend on reaching into communities for their effectiveness.

Community participation and social inclusion are now ideas of good currency. They are intuitive ideas for many and influence the way politicians think. Communities think this way as they search for quality in communal life. With this emphasis on community, there is a shift towards young people and their development as the pivot for local initiatives. This shift in concern for young people is a threshold test for the capacity of our communities to be nurturing and protective environments. 
A colleague questioned, 'Has it ever been shown, by before-and-after studies, that community development or building community capacity has a beneficial outcome?' This question causes us to take stock. It is a strongly held view in health and welfare that the nature of communities and the relationships they support are fundamental to social health and wellbeing. Theologians explore this very connection. ${ }^{5}$

There are data to show that communities with material resources, social and psychological support, shared values, reinforcing psychological and social networks, supportive family structures, teachers, physicians and health care, artists, and, some sense of purpose for living, have better health and wellbeing than those that do not. ${ }^{6}$ By creating these attributes in communities, we believe health will be improved.

Our knowledge of the relationship between community and health comes mainly from the evidence of negative effects, and historical precedents, such as the morbidity and mortality associated with extreme national poverty, social class, occupational health, indigenous peoples, fractured inner-city communities, homeless populations, marginalised groups and historical trends that show improvements with economic and social development. ${ }^{7}$

\section{HEALTH DEVELOPMENT}

David Legge describes health development in terms of conditions, pathways, agents and partnerships. ${ }^{8}$ The agents are the practitioners and organisations of public health, practitioners and organisations of health care, stakeholders, and policy makers in the 'other sectors' of social practice and citizens. The preconditions for health are access to basic material resources, security from material hazard, access to personal health care including personal preventive services and healthy and safe patterns of living. The pathways to health, he argues, are through partnerships including the people whose health is at stake. Thus the metaphor in health development is 'partnerships' and 'strategies of practice' rather than specific disease interventions characteristic of much public health. There are obvious synergies with community development.

The effectiveness of community development is most obvious in developing countries and in situations where marginalised groups can be assisted. This is being attempted in outer urban localities of South West Sydney. ${ }^{9}$ But the capability of communities to change must be treated cautiously. Tony Vinson, emeritus professor of social work, restudied the communities he researched in the 1970s and found the inequalities persisting 30 years later. ${ }^{10} \mathrm{~A}$ report of the health inequalities in the London Borough of Camden showed the differentials reported by Charles Booth in his survey of 1896 were exactly reproduced a century later. ${ }^{11}$

\section{Grand schemes}

Western governments are to an increasing extent taking up social-health issues to do with social capital and connectedness. Public health concerns are moving beyond the issues of nutrition, shelter, health services, access to health care and protection against infection, to issues bound up with our modern existence, social and community objectives and our relationships. That is not to deny the importance of material welfare and equity, and the effect of epidemic diseases.

There are many national and state initiatives in Australia that exhibit the themes of community partnerships, particularly in regard to young people-their future and their connectedness:

- National Mental Health Plan;

- Mental Health Promotion and Prevention National Action Plan;

- National Health Outcomes for Young People;

- National Aboriginal and Torres Strait Islander Health Strategy;

- Stronger Families and Communities Strategy;

- National Injury Prevention Strategic Framework;

- National HIV-AIDS and hepatitis C strategies;

- Putting Families in the Picture: Early Intervention into Youth Homelessness;

- Reconnect-Youth Homelessness Strategy (Department of Family and Community Services);

- Youth Pathways;

- Pathways to Prevention: Developmental and early intervention approaches to crime in Australia, part of the National Campaign Against Violence and Crime;

- National Public Health Partnership;

- Partnerships against domestic violence;

- National Drug Strategic Framework: Building Partnerships;

- National Framework for Suicide Prevention LIFE: Living Is For Everyone.

To take a few examples from these, the National AntiCrime Strategy says:

'Only in recent years has much scientifically persuasive evidence emerged that interventions early in life can have long term impacts on crime and other social problems such as substance abuse." 12

'At a broader level, protective factors can be enhanced by strengthening the capacity of a community to intervene positively in the lives of children, and by building facilities or social structures that support involvement and attachment, that help maintain a civil society rather than an oppositional culture. ${ }^{13}$ 
The Prime Minister's Task Force on Youth Homelessness says:

'The Taskforce believes that prevention approaches work most effectively when directed to building resilient families and communities. Resilient families are those with access to the skills and resources needed to withstand individual stresses and conflict. Similarly, resilient communities are those that can pull together and share resources so as to provide a better response to those most in need. ${ }^{14}$

The Mental Health Promotion and Prevention National Action Plan says, for children aged 5-11 years:

'... effective prevention of mental health problems can be achieved through: positive parenting, mental health promoting school programs that enhance life skills and resilience, foster a supportive school environment, support a school culture which links the community and school communities, that promote optimistic thinking, and which promote self efficacy and reduce aggressive behaviours.' ${ }^{15}$

\section{Early life}

The above strategies and programs emphasise the influence of early life events and nurture in childhood on outcomes in adolescence and adult life. Indeed, they frequently draw on the same research evidence.

The New South Wales' Government's Plan of Action following the Drug Summit in 1999 invested strongly in the Families First program. Families First aims to support parents expecting or caring for a new baby, infants and young children and to assist families build connections with their communities. It involves home visiting by volunteers and professional personnel and it is a universal program. ${ }^{16}$

Such simple and sensible interventions, which build on mutual support, have wide benefits and lessen inequalities. This must mean that human services at the local level should be run as partnerships. Further, central government initiatives such as drug strategies or policies to deal with youth unemployment or school retention, with overlapping goals, are more sensibly run together as 'whole of government' programs.

\section{Health initiatives}

In 1999-2000 the Ministerially-appointed Health Council reviewed New South Wales' health services. An important result has been the new arrangements of clinical governance involving partnerships between clinical service providers, managers and government. Another highly significant partnership is the greater community participation with area health services. ${ }^{17}$

The New South Wales directions for public healthHealthy People 2005-point to actions based on partnerships between health services and other agencies to develop and enhance community capacity. ${ }^{18}$ There are five principles: a population focus, a focus on prevention, promotion and early intervention, working in partnership, reducing health inequalities and effective and sustainable action. ${ }^{18}$ The NSW Department of Health proposes that this can be achieved through a Framework for Action divided into three streams for health improvement: healthier people, healthier places, and reducing health inequalities (Table 1). ${ }^{18}$

\section{TABLE 1}

FRAMEWORK FOR ACTION FOR HEALTH IMPROVEMENT IN NSW:

1. Healthier People

- Chronic Disease Prevention

- Healthier Childhood

- Mental Health Promotion

- Oral Health Promotion

2. Healthier Places

- Indigenous Environmental Health

- Fall Prevention among Older People

- Health Promoting Schools

- Regional Public Health Plans

- Smoke-Free Public Places

- Controlling Communicable Disease

3. Reducing Health Inequalities

- Health Improvement Planning

- Community Partnerships and cross-agency collaboration

Source: Public Health Division. Healthy People 2005-New Directions for Public Health in NSW. Sydney: NSW Department of Health, 2000. ${ }^{18}$

Thus state-sponsored public health takes a strong stand on community development and partnerships to improve health outcomes for the state as a whole.

\section{CONCLUSION}

There are political and social policy movements which aim to promote community development at the local level. These approaches offer real hope that socially excluded groups can be incorporated into modern public health. Many initiatives pivot around young people and their futures and can be regarded as true prevention and public health. As society deals with the existential fallout from modern life, these ideas should be seized by the public health community as a paradigm consistent with their health objectives, including the promotion of equity. Strong cooperation across disciplines will be required for implementation and research. 


\section{REFERENCES}

1. Howard J. Transcript of the Prime Minister's Speech. National Press Club, Canberra, 8 December 1999. www.pm.gov.au/ news/speeches/1999/pressclubr0612.htm.

2. Turner D. ' $360^{\circ}$ Accountability' Exploring Community Partnerships, their contribution to developing "joined up government" approach and to community empowerment; concentrating upon the issues of accountability within this emerging strategic and funding relationship. Draft Discussion Paper. Sydney: Enterprise and Career Education Foundation, October 2001.

3. Better Health Commission. Looking Forward to Better Health. Canberra: Australian Government Publishing Service, 1986.

4. Jalaludin B, Chey T, Mohsin M, and Bauman A. Health in South Western Sydney, Epidemiological Profile, 2000. Liverpool, NSW: Epidemiology Unit, South Western Sydney Area Health Service, 2000.

5. Lamb WWH. Towards a Christian Public Selfhood: A Philosophical Discussion. Spirit of Australia: Religion in Citizenship and National Life. Howe B and Nichols A (editors). Adelaide: Australian Theological Forum, Openbook Publishers, 2001.

6. Berkman LF, Glass T, Brisette I, and Seeman TE. From social integration to health: Durkheim in the new millennium. Soc Sci Med 2000; 51: 843-857.

7. Royal Australasian College of Physicians. For richer, for poorer, in sickness and in health. Sydney: Royal Australasian College of Physicians, 1999.

8. Legge D. Public Policy Perspective. Perspectives in Health Inequity Harris E, Sainsbury P and Nutbeam D (editors). Sydney: Australian Centre for Health Promotion, 1999.
9. Harris E, Sainsbury P, Nutbeam D (editors). Perspectives on Health Inequality. Sydney: Australian Centre for Health Promotion, 1999.

10. Vinson T. Unequal in life: the distribution of social disadvantage in Victoria and NSW. Melbourne: Ignatius Centre for Social Policy Research, 1999.

11. Dorling D, Mitchell R, Orford S, Shaw M, and Smith GD. The Ghost of Christmas Past: Health effects of poverty in London in 1896 and 1991. BMJ 2000; 321: 1547-1551.

12. National Crime Prevention Authority. Pathways to Prevention: Developmental and early intervention approaches to crime in Australia. Canberra: Attorney General's Department, 1999; 4.

13. National Crime Prevention Authority. Pathways to Prevention: Developmental and early intervention approaches to crime in Australia. Canberra: Attorney General's Department, 1999; 30.

14. Prime Ministerial Youth Homeless Taskforce. Report Putting Families in the Picture: Early intervention into Youth Homelessness. Canberra: Commonwealth Department of Family and Community Services, 1998; 16.

15. Prime Ministerial Youth Homeless Taskforce. Report Putting Families in the Picture: Early intervention into Youth Homelessness. Canberra: Commonwealth Department of Family and Community Services, 1998; 14.

16. Office of Children and Young People. Families First: A Support Network for Families Raising Children. Sydney: Office of Children and Young People, 1999.

17. Report of the NSW Health Council A Better Health System for NSW 03/2000. Sydney: NSW Department of Health, 2000.

18. Public Health Division. Healthy People 2005-New Directions for Public Health in New South Wales. Sydney: NSW Department of Health, 2000. 